\title{
The Nucleus 22-Channel Cochlear Implant System
}

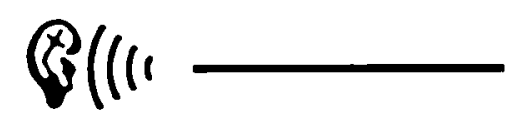

James F. Patrick, MSEE; Graeme M. Clark, FRACS

Cochiear Proprietary Limited, New South Wales, Australia (J. F. P.) and Department of Otolaryngology, Royal Victoria Eye and Ear Hospital, East Melbourne, Victoria, Australia (G. M. C.)

\begin{abstract}
Cochlear implants have become the treatment of choice for profoundly deaf adults and children who obtain little or no benefit from conventional amplification. Sounds are translated into small electric currents that stimulate the auditory nerves in the cochlea and generate hearing sensations. The Nucleus cochlear implant is the result of more than $20 \mathrm{yr}$ of research and development, first at the University of Melbourne, Australia and later by Cochlear Proprietary Limited (Sydney, Australia) in collaboration with the University of Melbourne. Today, the cochlear Mini-22 implant system is approved by the United States Food and Drug Administration (FDA) for use in adults and children, and has been implanted in more than 3000 patients worldwide. Although this chapter describes the cochlear implant system and clinical issues related to its use in children, much of the material has been derived from experience with adults. Furthermore, the Nucleus system is not static. It is being continually improved both in performance and ease of use. The purpose of this chapter is to describe developments leading up to and including the present Nucleus cochlear implant system. Other chapters in this issue present results and procedures relating to pediatric applications of the device.
\end{abstract}

\section{HISTORICAL DEVELOPMENT}

BEFORE IMPLANTING IN human subjects, initial research was conducted on experimental animals to determine how best to stimulate the auditory nerve electrically. These studies indicated that variations in stimulus rate were not adequate to convey significant amounts of speech information (a significant limitation of single-channel cochlear implants) (Tong, Blamey, Dowell, \& Clark, 1983). For this reason, it was appropriate to begin development of an experimental pros- priate to begin development of an experimental prosthesis having an array of electrodes that would enable speech frequencies to be presented as place of stimulation. In addition, previous work on experimental animals had shown that a plug and socket for percutaneous stimulation was frequently associated with infection. Therefore, it was considered most appropriate to design a completely implantable receiver/stimulator, which would be controlled by a transcutaneous link to an external speech processor.

The receiver/stimulator that resulted from this research was implanted in the first adult subject on August 1,1978 at the University of Melbourne. The initial research was carried out on a single subject, as it was considered important to obtain maximum information from an intensive study on one subject before extending experimental risks to other subjects. The research goal was to determine if the subject could understand connected speech. In designing the study we also had to achieve a balance between carrying out thorough basic research investigations and providing the patient with a practical means of help. Our first investigations confirmed that the patient could perceive different pitch sensations when different electrode sites were stimulated. They also confirmed that pitch perceptions varied with the rate of stimulation, but that discrimination of frequency differences above 200 to 300 pulses/sec was extremely limited (Tong, Black, Clark, Forster, Millar, \& O'Loughlin, 1979).

After these initial psychophysical studies, it was decided to use a speech processing strategy that was physiologically based (Laird, 1981). This speech processor was designed to model basilar membrane motion and the tuning of auditory nerve firing. It filtered the speech frequencies so that appropriate electrodes could be stimulated at intensities that were related to the filter outputs. Unfortunately, the speech perception results were very poor. It was thought that simultaneous stimulation occurring at the different electrode sites created summation of the current fields leading to unpredictable variations in loudness. As a result of these findings, it was considered desirable to provide nonsimultaneous (sequential) stimulation, and to preprocess the speech signal in order to simplify it.

When this first subject was asked to select vowel tokens representing the percept of the presentation of

0196/0202/91/1204-0003\$ $\$ 03.00 / 0$ - EAR AND HEARING Copyright (C) 1991 by Williams \& Wilkins - Printed in the U.S.A. 
brief pulse trains to different electrodes, he selected vowels with second formant (F2) frequencies that corresponded, in order, to the place of the stimulating electrode. Psychophysical studies also showed that rapid changes in stimulation site along the electrode array could be used to convey rapidly time varying information, such as the frequency of spectral peaks (Tong, Clark, Blamey, Busby, \& Dowell, 1982). This led to development of an F0/F2 speech processing strategy which presented the important F2 cue as place of stimulation and voicing frequency $\mathrm{F} 0$ as rate of stimulation (Tong et al, 1979). The frequency of the F2 was used to determine the site of electrical stimulation and the appropriate current level was proportionate to the intensity of the overall speech envelope.

Standard audiological tests were administered and it was very exciting to find that this subject could perceive speech, especially in an open set format. The open set speech tests, carried out according to a strict protocol, were from standard sets of words and sentences, with each test list being used only once. The patient obtained up to a $400 \%$ improvement in test scores using electrical stimulation combined with lipreading, compared to when he was lipreading without sound. He also achieved 10 to $14 \%$ on these tests when using electrical stimulation alone. Performance on open set tests is considered a good indicator of the ability to understand connected speech. Thus, these results were an encouraging and objective measure that the F0/F2 speech processor strategy was of practical benefit to the patient.

Two more experimental subjects were implanted in 1979; the first used the device effectively, whereas for the second there were design problems which prevented adequate testing. These early results offered sufficient promise for an effective clinical treatment that Nucleus Limited of Sydney, Australia (a company with extensive experience in cardiac pacemakers and the parent company of Cochlear Pty Ltd) undertook to develop, manufacture, and market the cochlear implant.

The development of the first Nucleus 22-electrode cochlear implant commenced in 1981 and laboratory tests were completed in 1982. After an initial series of six postlinguistically deafened adult subjects implanted at the University of Melbourne, a clinical trial began in the United States under the auspices of the FDA in May 1982.*

The University of Melbourne continued further studies on experimental animals to help ensure that the electrical stimulus parameters used would not cause damage to spiral ganglion cells, and that the materials used to construct the implant were biocompatible. Studies also were carried out on human temporal bones to ensure that implantation of the electrode array into the cochlea would not lead to any significant trauma.

The outcome of these clinical and animal studies demonstrated that the Nucleus F0/F2 multiple-electrode prosthesis was safe and effective. It was approved

\footnotetext{
"See Chapter 2 for details regarding FDA requirements for medical
} devices. by the FDA in October 1985 for use in postlinguistically deafened adults.

Psychophysical and speech processing research continued at the University of Melbourne to see if speech perception performance could be improved by adding more spectral information (the first formant, F1) to the coding strategy. The research initially consisted of developing an acoustic model of electrical stimulation using the F0/F2 strategy and assessing it with normalhearing subjects (Blamey, Martin, \& Clark, 1985). The model was then modified to provide $F 1$ information as well. The addition of $F 1$ provided significant improvements in speech perception scores. This F0/F1/F2 strategy was implemented for use with cochlear implant patients. This strategy specifies stimulation of a more basal electrode (corresponding to F2) and a more apical electrode (corresponding to $\mathrm{Fl}$ ) in rapid succession. Both $F 1$ and $F 2$ electrodes are stimulated at the F0 rate. Similar improvements in performance to those obtained with the acoustic model were observed in implanted patients (Dowell, Seligman, Blamey, \& Clark, 1987). After these studies, the F0/F1/F2 strategy was incorporated into the Nucleus speech processor, which was approved by the FDA for distribution in May 1986. Once proven safe and effective in postlinguistically deafened adults, it was considered appropriate to extend the application of multi-electrode implant technology to children.

For a variety of reasons (e.g., skull size, language competence, ability to program), the first patient implanted under the age of $18 \mathrm{yr}$ was an adolescent (see Mecklenburg et al, Chap. 2). Before implanting younger children, it was necessary to reduce the size of the receiver/stimulator so that it could be seated in the thinner skull of a younger child. An improved method of holding the transmitting coil was also required because the existing headset was rather cumbersome. The Mini 22 receiver/stimulator, which is described below, incorporated a rare earth magnet to hold the external transmitting coil in place, and was small enough to be implanted in children as young as $2 \mathrm{yr}$ of age.

In order to improve performance and reduce the size and weight of the speech processor, further research was undertaken. This resulted in a new, smaller "mini speech processor" (MSP) that was just half the size and weight of the previous model processor (wearable speech processor: WSP). The electronic components of the MSP were completely new and it could be programmed with the new coding strategy known as "multipeak." The multipeak strategy measures the frequencies of the dominant spectral peaks in the frequency ranges which normally contain the first two speech formants (F1 and F2), and the amounts of energy in these two bands (called A1 and A2). In addition, the amounts of energy in three higher bands, A3 (2000 $2800 \mathrm{~Hz}), \mathrm{A} 4(2800-4000 \mathrm{~Hz})$ and A5 $(4000-7000 \mathrm{~Hz})$ are measured. Extensive tests of the MSP using the multipeak coding strategy (Dowell, Whitford, Seligman, Franz, \& Clark, 1989; Skinner, Holden, Holden, Dowell, Seligman, Brimacombe, \& Beiter, 1991) dem- 

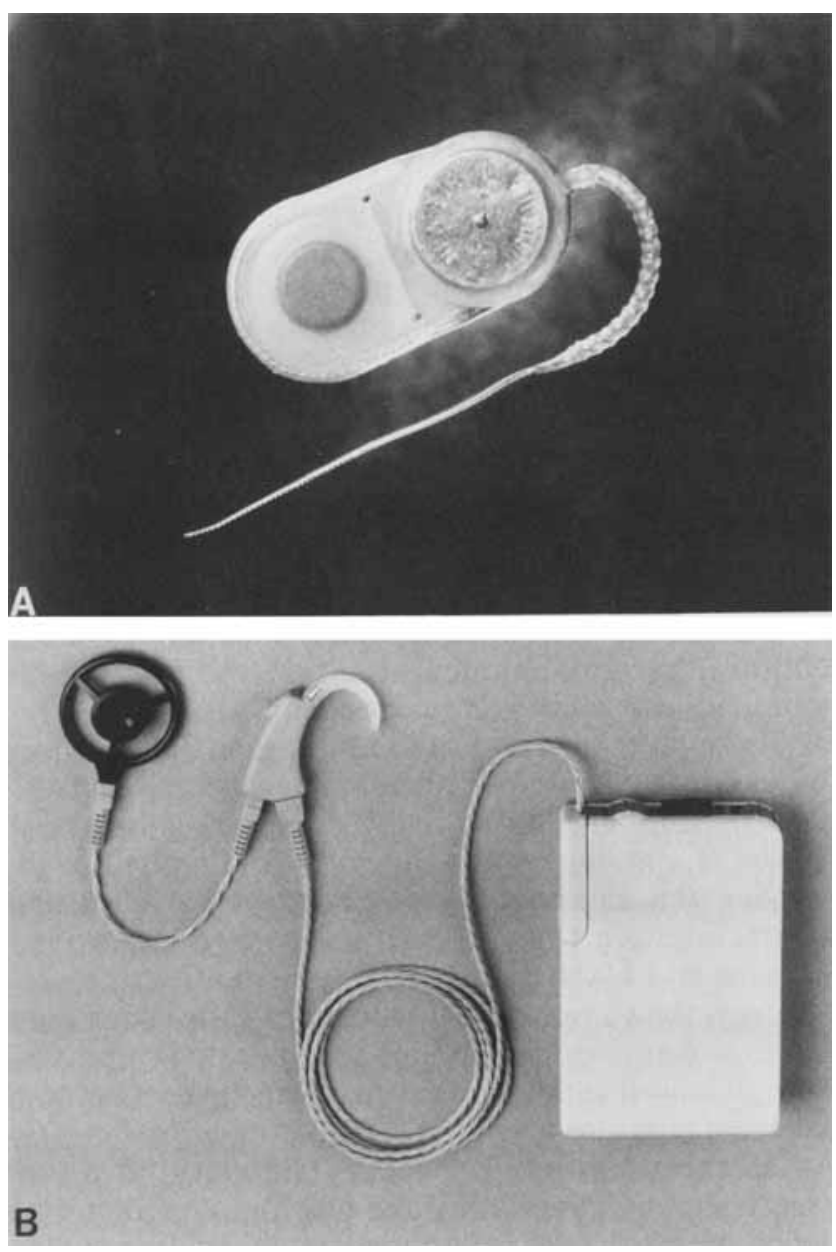

Figure 1. (A) The Mini-22 Cochlear Implant. (B) The Mini Speech Processor (MSP) and microphone headset.

onstrated a significant performance improvement over the F0/F1/F2 strategy. $\dagger$

\section{THE MINI-22 IMPLANT SYSTEM}

The Mini-22 implant system (Fig. 1A) consists of an array of 22 electrodes which is surgically implanted inside the cochlea and is connected to a small receiver/ stimulator unit placed under the skin behind the ear. An externally worn speech processor (Fig. 1B) determines which electrodes are to be stimulated, based on incoming sounds which are picked up by a directional microphone worn at ear level. This information is passed to the implanted stimulator by a transmitter coil, which is held against the skin above the stimulator by a magnet. The transmitter coil is electromagnetically linked to a coil in the implanted receiver, and this link is also used to provide the power needed by the receiver.

†A detailed description of the research and development summarized above is found in Cochlear Prostheses (Clark, Tong, \& Patrick, 1990), including details of the psychophysics and speech perception studies which underpin the speech processing strategies and the hardware which is outlined below.
Programming the speech processor is accomplished through use of a computer-based diagnostic and programming system (DPS) (Fig. 2). The flexible DPS allows the clinician to set individual electrodes to match the specific requirements of each patient. This system also accommodates any changes in electrical requirements that may occur in a given patient across time. Detailed descriptions of programming techniques in children using the DPS are contained in Chapter 4 (Beiter, Staller, \& Dowell).

\section{The Implant (Receiver/Stimulator and Electrode Array)}

The electrode array comprises 22 evenly spaced platinum band electrodes, tapering from a diameter of 0.6 to $0.4 \mathrm{~mm}$ at the tip of the array. The electrodes are supported by a molding of silicone rubber, and proximal to the active electrodes are an additional 10 platinum bands which provide extra stiffness so that the array can be inserted up to $25 \mathrm{~mm}$ into the scala tympani. With a complete electrode insertion, the most basal electrode is some 8 to $10 \mathrm{~mm}$ inside the round window.

The electrode array has a very smooth surface, is flexible, yet stiff enough for easy surgical insertion into the cochlea (Clark et al, 1979; Patrick \& MacFarlane, 1987). In the event of device failure or, more likely, the desire to upgrade the implant at some time in the future, the electrode array can be atraumatically removed from the cochlea (Clark et al, 1987a). This is important, as it means that a connector between the stimulator unit and the electrode array is not necessary.

The stimulator circuits are housed in a hermetically sealed titanium/ceramic capsule, and the receiver coil is embedded in silicone rubber. A powerful magnet, isolated from body fluid, is mounted in the center of the receiver coil. The coil/magnet assembly can be bent easily to allow the shape of the implant to conform to skull curvature. As described earlier, the materials in

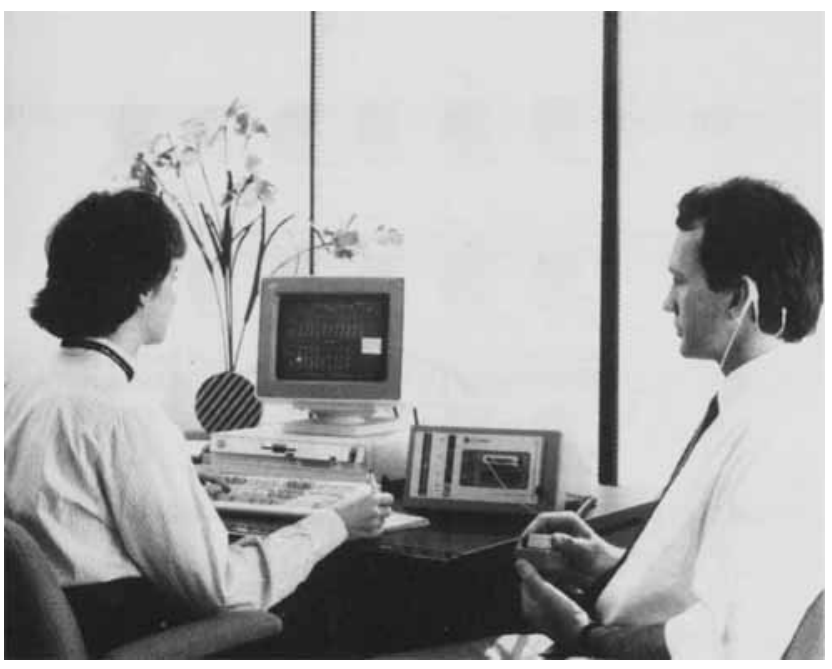

Figure 2. The diagnostic and programming system. 
contact with tissue were selected because of their known biocompatibility.

The stimulator electronics consist of a few power supply components and a custom-made integrated circuit. This circuit decodes the control information from the $2.5 \mathrm{MHz}$ electromagnetic link to determine which electrodes are to be stimulated and at what level. All data are digitally encoded, and if the correct data sequence is not received, then stimulation is inhibited. The most important stimulus parameters are: (1) sequential biphasic pulsatile stimulation; (2) Bipolar stimulation (between any pair of electrodes), or on common ground (where stimulation occurs between one active electrode and a ground or return made up of all other electrodes linked together). (3) current source stimulation; (4) the output current is between $15 \mu \mathrm{A}$ and 1.5 $\mathrm{mA}$; (5) 239 current amplitudes, exponentially spaced; (6) variable pulse width 20 to $408 \mu \mathrm{sec}$; (7) total pulse rate in excess of 1600 pulses/sec.

Figure $3, \mathrm{~A}$ and $\mathrm{B}$, illustrates the biphasic charge balanced stimulus and how these biphasic pulses are presented to nearby pairs of electrodes on the electrode

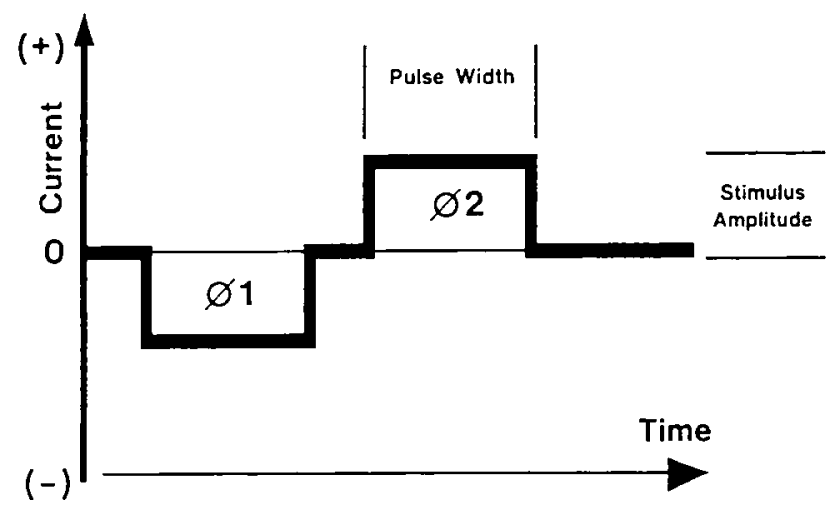

A

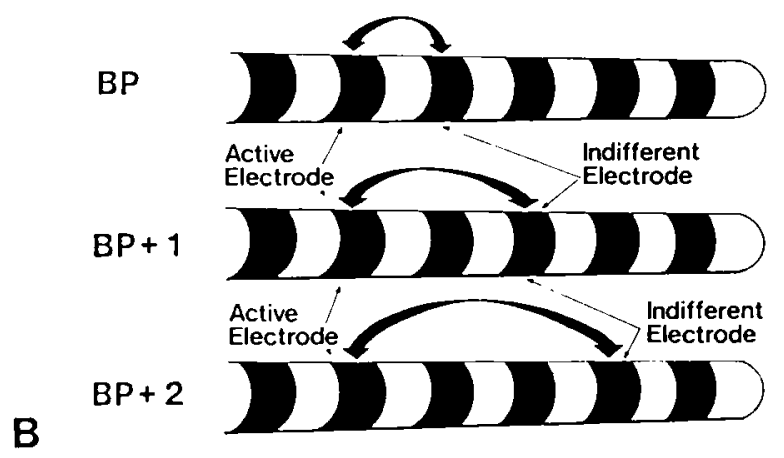

Figure 3. (A) Biphasic stimulus pulse. (B) Electrode selections for bipolar (BP) and more widely spaced stimulation modes (BP +1 , BP $+2)$. The electrode array contains 22 electrodes, providing 21 bipolar pairs with the $\mathrm{BP}$ configuration, 20 pairs with $\mathrm{BP}+1$ and so on. The widest electrode spacing normally used is $\mathrm{BP}+3$. array. The electrode spacing can be changed from bipolar, in which adjacent electrodes are stimulated, to wider electrode spacings, which are used if the bipolar mode does not produce sufficiently loud sounds. Alternatively, an active electrode can be selected for stimulation against all other electrodes connected together, as illustrated in Figure 4. The stimulus current delivered by the active electrode is returned through all other electrodes in the common ground mode. Common ground has been used quite widely with children, because it has a very important fail-safe advantage over bipolar stimulation. During surgical insertion it is possible to damage the insulation on an electrode band so that two distant electrodes may at some later time short momentarily together. If bipolar stimulation is used and a short circuit condition exists, the broader current spread can result in uncomfortably loud sensations. In contrast, a short-circuited electrode will produce no stimulation at all in common ground.

Although the percept of loudness may be controlled by varying the number of remaining neural elements that are stimulated (electrically by changing the overall mode of stimulation), loudness also is controlled by varying the charge density applied at the electrodeneural interface. Charge density is related to the product of pulse width and amplitude. In the multipeak coding strategy, the stimulus level parameter varies both pulse width and amplitude to obtain the most power-efficient stimuli as well as the smallest charge increment between adjacent stimulus levels.

Only one pair of electrodes is stimulated at a time (sequentially), eliminating the possibility of direct interaction between stimulating currents to different electrode pairs. Sequential stimulation also simplifies the stimulator circuitry, as a single current source circuit can be shared by all electrodes (Crosby et al, 1984). When no stimuli are being delivered, all electrodes are connected together. This ensures that all electrodes rest in a discharged state (Robblee et al, 1987).

The digitally coded radio frequency link between the speech processor and the stimulator gives reliable and virtually error-free performance. In laboratory experiments, it was found that although extremely strong electromagnetic fields could ultimately stop the link entirely, the only two effects for the implant user would be a low level of background noise and then a small reduction in loudness before the stimulation ceased.

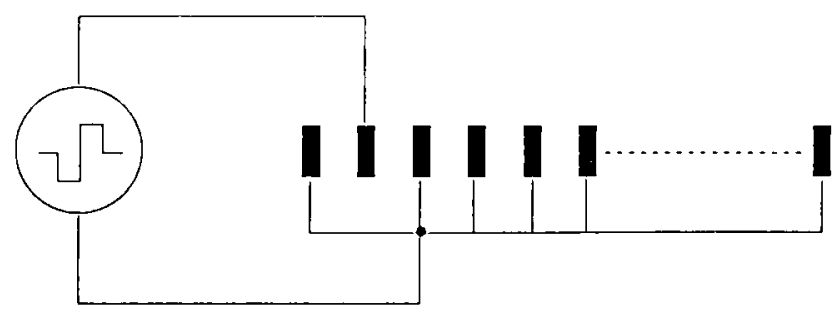

Figure 4. Typical current distribution for the common ground stimulation mode. 
Once the user moved out of the strong electromagnetic field, the stimulator would resume normal operation.

The Mini-22 implant uses proven pacemaker technology to provide a versatile and reliable implant, and unique construction techniques have allowed the stimulator to be made small enough to be implanted in children as young as $2 \mathrm{yr}$ of age. The electronic circuit contained in the stimulator unit is essentially the same as it was in 1982, when the forerunner to the Mini-22 (the standard receiver/stimulator) was first implanted. Since that time there have been three changes in the external speech processor, with each change resulting in a significant improvement in patient performance with the system. Patients have been able to take advantage of these improvements without the need for additional surgery.

\section{The MSP Speech Processor}

The MSP speech processor can be programmed to carry out the multipeak, $\mathrm{F} 0 / \mathrm{F} 1 / \mathrm{F} 2$, and $\mathrm{F} 0 / \mathrm{F} 2$ strategies, and also can be used to investigate other coding strategies. The most widely used strategy is multipeak.

The speech processor attempts to mimic the normal function of the ear by stimulating different regions of the cochlea according to the spectral content of the speech signal. With the multipeak coding strategy, two electrodes are selected for stimulation on the basis of the $F 1$ and $F 2$ frequency and amplitude estimates, and three fixed basal electrodes are used to represent the amplitudes from the A3, A4, and A5 filter bands (See Fig. 5). The amplitude of stimulation to any electrode is always within the patient's measured dynamic range. For any acoustic signal, the stimulation level chosen is proportional to the signal energy level within the filter band (i.e., A 1-A5) and the patient's measured sensitivity for that electrode(s).

The rate of stimulation is equal to the voicing frequency for voiced sounds (or low-frequency periodicity of environmental sounds) and is at a randomized rate between $200 \mathrm{~Hz}$ and $300 \mathrm{~Hz}$ for unvoiced sounds that

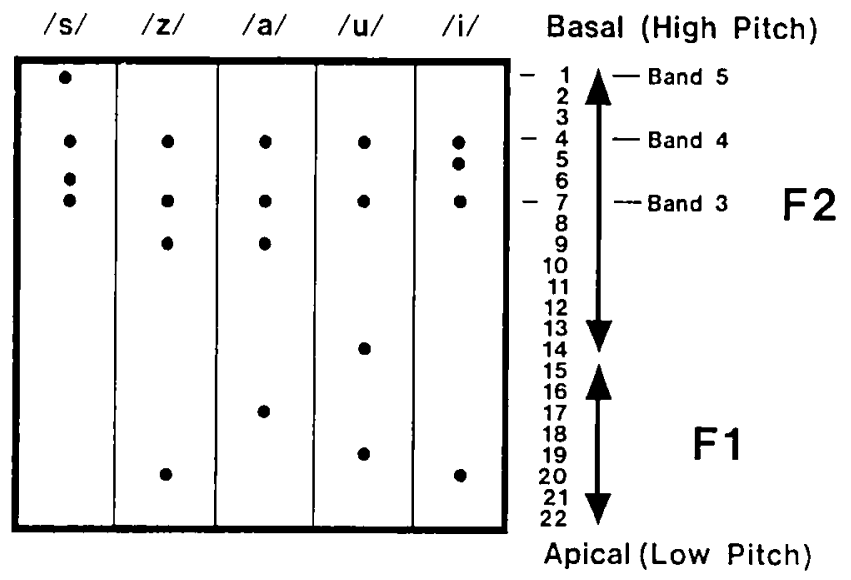

Figure 5. Electrical stimulation patterns for the multipeak coding strategy. have little energy below $1000 \mathrm{~Hz}$. Thus, low frequency information is presented explicitly as stimulation rate, whereas the remaining spectral content of the signal is represented by the place of the stimulating electrodes. Because unvoiced stimuli have little energy in the $F 1$ frequency range, an electrode representing F1 is not selected for stimulation. It is replaced with the fixed electrode representing the frequency band that extracts information above $4000 \mathrm{~Hz}$ (A5). For voiced stimuli there is little high-frequency energy present above 4000 $\mathrm{Hz}$, therefore, the fixed electrode representing the 4000 to $7000 \mathrm{~Hz}$ band is not stimulated. Figure 6 , A and B, shows the electrode stimulation sequence for voiced and unvoiced (no low-frequency periodicity) sounds. For any acoustic input, the four electrodes chosen to represent the spectral energy in the signal are stimulated sequentially from base to apex.

Sometimes it may not be feasible to use multipeak, for example, when the cochlea is ossified and electrode insertion is incomplete. In such cases, a coding strategy which transmits a reduced amount of spectral information, such as $\mathrm{F} 0 / \mathrm{F} 2$ or $\mathrm{F} 0 / \mathrm{F} 1 / \mathrm{F} 2$, may be used in order to make best use of the limited number of electrodes available.

The MSP speech processor uses a combination of digital and analog circuits. A custom digital signal-

Multi-Peak Speech Coding Strategy for Voiced Sounds

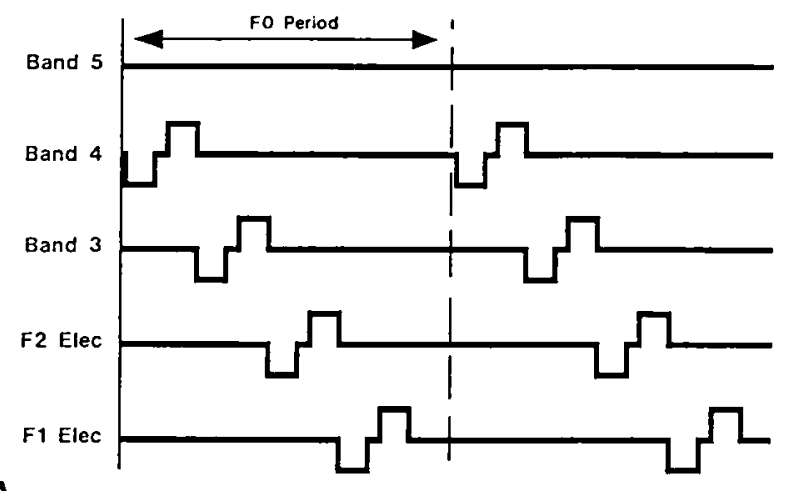

A

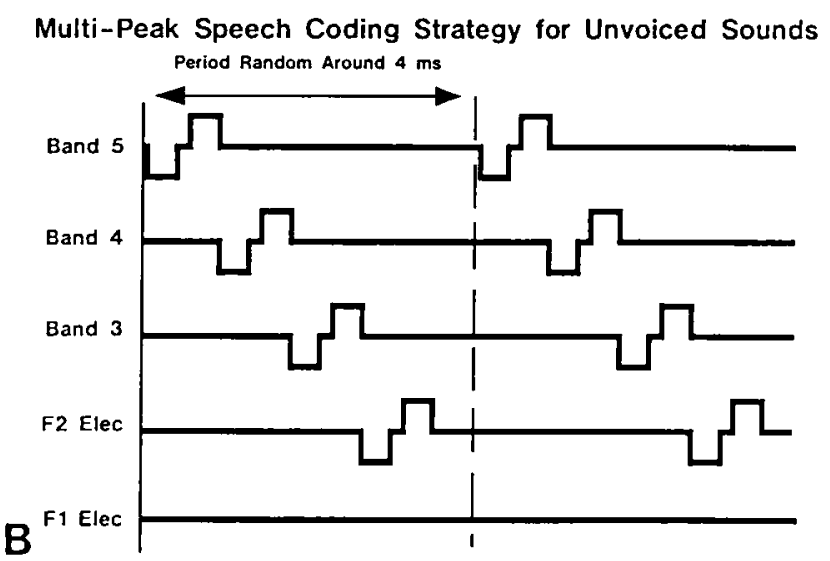

Figure 6. The multipeak coding strategy: (A) voiced sounds; $(B)$ unvoiced sounds. 
processing (DSP) integrated circuit is used to control the overall speech processor operation, whereas a custom analog filter chip provides additional signal processing capacity. This mix of circuit types is very powerefficient, and a single rechargeable nickel-cadmium AA cell typically gives 1 day's use of the processor between battery charges.

\section{The Microphone Headset}

The microphone headset uses a conventional directional microphone worn at ear level. The microphone case also houses part of the transmitter circuit, so that inexpensive cable can be used to connect the speech processor to the headset. The magnetic strength of the headset transmitting coil can be adjusted to suit different depths of implant placement and hair type. This is accomplished by adjusting the position of the magnet or by selecting a magnet of different strength.

\section{Battery Charger}

The MSP can be powered by either disposable or rechargeable batteries. High capacity nickel-cadmium rechargeable batteries and a high-rate battery charger are supplied with the speech processor. In order to ensure that the speech processor is always functional, rechargeable batteries are recommended, with nightly recharging.

\section{Use of Assistive Devices}

FM Systems In listening conditions where the $\mathrm{S} / \mathrm{N}$ ratio is poor, such as a noisy classroom, children with cochlear implants can benefit from the use of FM systems. However, because the speech processor generates a radio frequency signal to control the implant, interference can occur if this signal is detected by the FM receiver. To control for such distortions, a special interface cable is used to connect the MSP to the FM receiver. There are a number of commercially available FM systems and the interface cables that interface with the MSP are system-specific.

Audio Input Selector The Audio Input Selector (AIS) is an optional accessory that was designed to interface between the processor and external sound sources such as induction loop systems, television, and radio (Fig. 7). It also has a microphone, which can be turned on or off, to pick up sound from the environment. The AIS monitors the audio output level from the alternative sound source and adjusts the signal level to match that required by the MSP. Although the AIS was primarily designed for adult use, it may also be of benefit to children in some listening situations.

\section{RELIABILITY}

In a device as complex as a cochlear implant, occasional device failures cannot be avoided. Obviously, failure of the receiver/stimulator has the most serious consequences for the patient, as its resolution requires a second surgery. As of December 31, 1990, over 3000

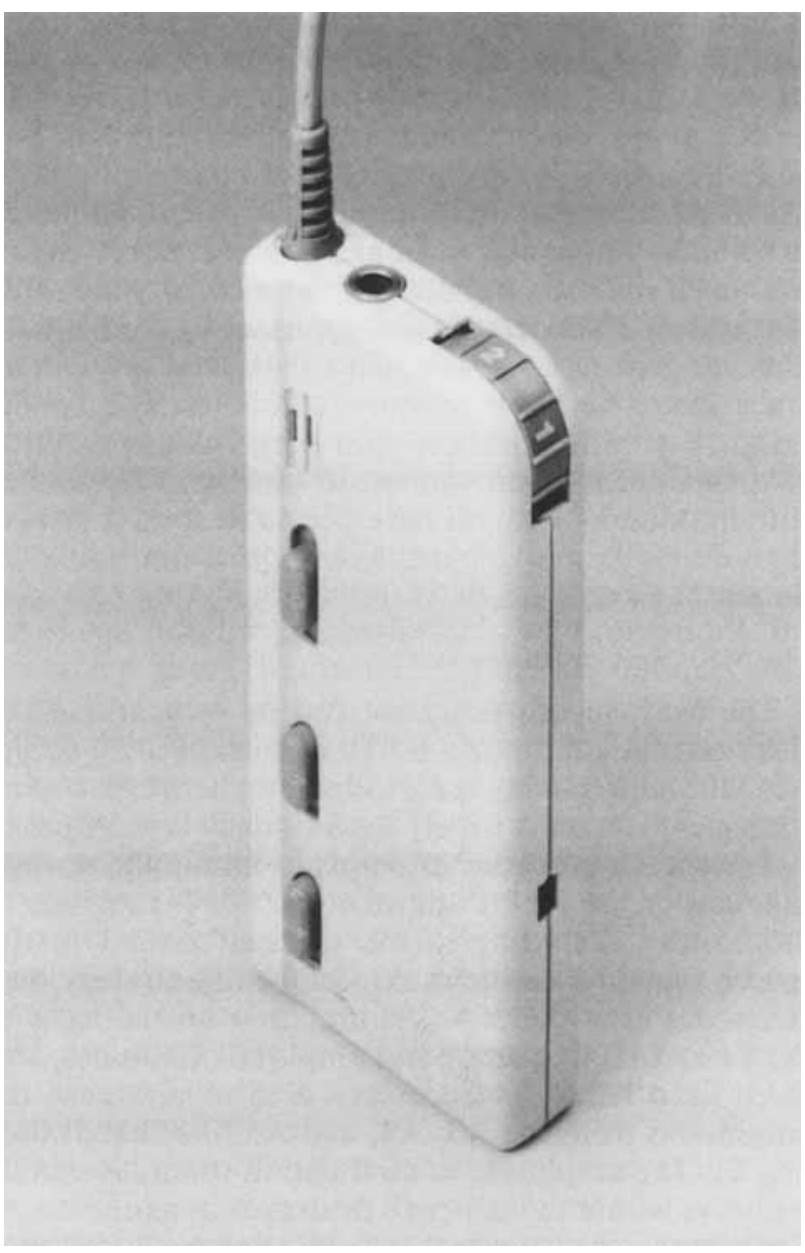

Figure 7. The Audio Input Selector (AIS).

patients had received either the standard or mini version of the Nucleus implant. Of these implants, $1.7 \%$ have failed internally. Device failures are systematically investigated and, if necessary, the design/production/ distribution process is modified accordingly.

In addition to the reliability of the implanted components, it is essential that the speech processor and headset also be as reliable as possible. As many clinicians know, patients often grow to be very dependent on the sound provided by the implant and find it very distressing to be without it for even a short time. Production prototypes must pass rigorous qualification tests before they are accepted for production. An active quality assurance program is aggressively implemented in an attempt to improve product quality. The reliability of electronic devices generally improves with manufacturing experience, and the cochlear implant should be no exception.

\section{THE FUTURE}

The performance of patients with cochlear implants will certainly continue to improve. The implant system of the future will present more speech information and 
do so more effectively than present systems. Although both sequential pulsatile stimulation and simultaneous analog stimulation can already provide excellent patient results, the future lies with sequential pulsatile strategies. In a recent study (Wilson, Lawson, Finley, \& Wolford, 1990), speech perception was evaluated using high rates of pulsatile stimulation in eight patients accustomed to multichannel analog stimulation. All eight patients improved their performance when using this high-rate sequential pulsatile strategy.

Improved patient performance can be expected as a result of advances in three areas. First, if the electrode systems can be improved, then it may be possible to increase the accuracy of the spectral representation by improving control over which groups of nerves are stimulated. Second, the transfer of temporal variations in the energy within different frequency bands can be improved through the use of higher pulse rates. Systematic psychophysical studies are needed to investigate the rates that will optimize the representation of temporal information in the speech envelope. Third, performance in noise can be further enhanced through use of intelligent signal processing. New higher speed, lower power technology will allow more complex signal processing to be carried out without an increase in power consumption. For many reasons, the wholly implanted and perfectly functional cochlear implant remains in the realm of science fiction, but with each improvement we take a step closer to that goal.

\section{REFERENCES}

Battmer RD. Die anpassung des CLARK/NUCLEUS cochlear implant. In Lehnhardt E and Hirshorn MS, Eds. Cochlear Implant. Berlin: Springer Verlag. 1986:133-144.

Blamey PJ, Martin LFA, and Clark GM. A comparison of three speech coding strategies using an acoustic model of a cochlear implant. J Acoust Soc Am 1985:77:109-217.

Busby PA. Roberts SA, Rickards FW. Dettman SJ. Altidis PM. Clark GM, and Tong YC. Results for the Nucleus multiple-electrode cochlear implant in two children. Proceedings of the 19th International Congress of Audiology, Israel, June 5-9, 1988.

Clark GM. Patrick JF, and Bailey QF. A cochlear implant round window electrode array. J Laryngol Otol 1979:93:107-109.

Clark GM, Pyman BC. Webb RL, Franz BK-HG, Redhead TJ, and Shepherd RK. Surgery for the safe insertion and reinsertion of the banded electrode array. In Clark GM and Busby PA. Eds. Int Cochlear Implant Symp Workshop, Melbourne, 1985, 1987a: 96(Suppl 128): 10-12.
Clark GM. Blamey PJ. Busby PA. Dowell RC. Franz BK-H. Musgrave GN. Nienhuys TG, Pyman BC. Roberts SA, Tong YC, Webb RL. Kuzma JA. Money DK. Patrick JF, and Seligman PM. A multiple-electrode intracochlear implant for children. Arch Otolaryngol 1987b;113:825-828

Crosby PA, Seligman PM, Patrick JF, Kuzma JA, Money OK, Ridler $\mathrm{J}$, and Dowell $\mathrm{R}$. The nucleus multichannel implantable hearing prosthesis. Acta Otolaryngol 1984:(Suppl. 411):9-12.

Dowell RC, Seligman PA, Blamey PJ, and Clark GM. Speech perception using a two formant 22-electrode cochlear prosthesis in quiet and in noise. Acta Otolaryngol 1987;104:439-446.

Dowell RC, Whitford LA. Seligman PM. Franz BK-H, and Clark GM. Preliminary results with a miniature speech processor for the 22 electrode Melbourne/Cochlear hearing prosthesis. In Sacristan T, Alvarezvicent JJ, Antolt F, and Candela. Eds. Proceedings of the XIV World Congress of Otorhinolaryngology. Head and Neck Surgery, Madrid, September 10-15, 1989. Amsterdam: Kugler and Ghedini, 1990.

Laird RK. A sound encoder for an implantable hearing prosthesis (Master's degree thesis). University of Melbourne, 1979.

Nienhuys TG. Musgrave G. Busby PA. Blamey PJ. Nott P. Tong YC. Dowell RC. Brown L. and Clark GM. Educational assessment and management of children with multichannel cochlear implants. Ann Otol Rhinol Laryngol 1987:96(Suppl 128):80-82.

Patrick JF and MacFarlane JC. Characterization of mechanical properties of single electrodes and multielectrodes. Ann Otol Rhinol Laryngol 1987:96:46-48.

Roblee LS, Cogan SF, Kimball AG, and Marren PJ. Development of neural stimulating electrodes and evaluation of their electrochemical reactions. Contract N01-NS-5-2379, National Institutes of Health, Seventh Quarterly Progress Report. March 1 to May 15. 1987.

Skinner MW, Holden LK, Holden TA, Dowell RC. Seligman PM. Brimacombe JA, and Beiter AL. Performance of Postlinguistically Deaf Adults with the Wearable Speech Processor (WSP) and Min Speech Processor (MSP) of the Nucleus Multielectrode Cochlear Implant 1991:12:3-22.

Tong YC, Black RC, Clark GM, Forster IC. Millar JB, and O'Loughlin BJ. A preliminary report on a multiple-channel cochlear implant operation. J Laryngol Otol 1979:93:679-695.

Tong YC, Blamey PJ, Dowell RC, and Clark GM. Psychophysical studies evaluating the feasibility of a speech processing strategy for a multiple-channel cochlear implant. J Acoust Soc Am 1983:74:7380.

Tong YC. Clark GM, Blamey PJ, Busby PA, and Dowell RC. Psychophysical studies for two multiple-channel cochlear implant patients. J Acoust Soc Am 1982:71:153-160.

Wilson BS, Lawson DT, Finley CC, and Wolford RD. Speech processors for auditory prosthesis. Quarterly Progress Reports 4 and 5. Neural Prosthesis Program, National Institutes of Health. 1990.

Address reprint requests to J. F. Patrick, Cochlear Proprietary Limited, 1 Woodcock Place, Lane Cove, New South Wales, Australia 2066. 


\section{University Library}

\section{- M M I E E R VA A gateway to Melbourne's research publications}

Minerva Access is the Institutional Repository of The University of Melbourne

Author/s:

Patrick, James F.;Clark, Graeme M.

Title:

The Nucleus 22-channel cochlear implant system

Date:

1991

Citation:

Patrick, J. F., \& Clark, G. M. (1991). The Nucleus 22-channel cochlear implant system. Ear and Hearing, 12(4, suppl.), 3S-9S.

Persistent Link:

http://hdl.handle.net/11343/27308 